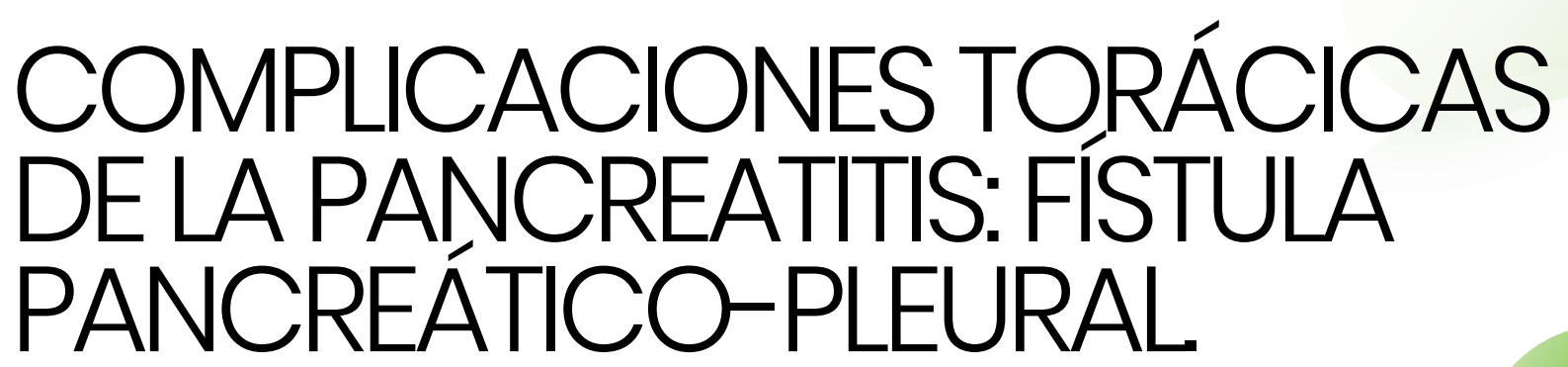

\title{
THORACIC COMPLICATIONS OF PANCREATITIS: PANCREATICO-PLEURAL FISTULA.
}

\section{Díaz Alcázar MM, Ruiz Escolano E}

Hospital Universitario Clínico San Cecilio. Granada.
Resumen

Hombre de 44 años con pancreatitis crónica alcohólica que refiere epigastralgia y disnea. La radiografía de tórax mostró derrame pleural derecho. Se realiza tomografía computarizada abdominal con hallazgo de colección líquida en la cabeza pancreática que se continúa con la crura diafragmática derecha y produce derrame pleural. El análisis del exudado pleural muestra amilasa aumentada.

Las complicaciones torácicas más comunes de las pancreatitis incl uyen derrame pleural y neumonía, mientras que la fístula pancreático-pleural es más rara. La fístula pancreática consiste en la disrupción inflamatoria del conducto pancreático. El líquido pancreático asciende a través de aperturas anatómicas del diafragma, habitualmente el hiato esofágico y el aórtico. El acúmulo torácico de líquido pancreático puede producir derrame pleural o pseudoquiste pleural o mediastínico. El diagnóstico se basa en pruebas de imagen, aunque a veces la fístula es difícil de visualizar. El análisis bioquímico del líquido pleural con aumento de amilasa confirma el diagnóstico.

\section{CORRESPONDENCIA}

María del Mar Díaz Alcázar

Hospital Universitario Clínico San Cecilio

18016 Granada

mmardiazalcazar@gmail.com

Fecha de envio: 22/09/2021

Fecha de aceptación: 11/10/2021
Palabras clave: pancreatitis, derrame pleural, fístula pancreático-pleural.

\section{Abstract}

A 44-year-old male with alcohol-induced chronic pancreatitis consults for epigastric pain and dyspnea. Right pleural effusion is observed in chest radiography. Abdominal computed tomography displays a liquid collection in the pancreatic head that is continued with the right diaphragmatic crus and determines the right pleural effusion. Pleural exudate tests show high amylase levels.

Common thoracic complications of pancreatitis include pleural effusion and pneumonia while pancreatico-pleural fistula is a rare complication. Pancreatic fistula consists of inflammatory disruption of the pancreatic duct. Pancreatic fluids extend upward through anatomical openings of the diaphragm, typically through the esophageal and aortic hiatus. Thoracic collections may consist of pleural effusions, pleural pseudocysts, or mediastinal pseudocysts. The diagnosis is based on imaging studies, although the canal connecting the pleural cavity and the abdominal cavity is difficult to visualize. The biochemical pleural fluid analysis shows an increased amylase activity and confirms the diagnosis.

Keywords: pancreatitis, pleural effusion, pancreaticopleural fistula. 


\section{Introducción}

Las complicaciones torácicas más comunes de las pancreatitis incluyen derrame pleural y neumonía ${ }^{1}$. Las enfermedades pancreáticas pueden complicarse con dos tipos de derrame pleural ${ }^{2}$. Uno de ellos se asocia con la pancreatitis aguda, habitualmente es pequeño y se localiza en la cavidad pleural izquierda ${ }^{2}$. En este derrame el líquido pleural se caracteriza por amilasa normal $(<100 \mathrm{U} / \mathrm{I})$ y baja concentración en proteínas $(<3 \mathrm{~g} / \mathrm{dl})^{2}$. El segundo tipo es el derrame asociado a una fístula pancreática-pleural que puede penetrar en la pleura, bronquios, mediastino o pericardio por el gradiente de presión entre abdomen y tórax².

Se presenta el caso de un hombre de 44 años con pancreatitis crónica alcohólica que consulta por epigastralgia de varios días de evolución a la que se sobreañade disnea en las últimas horas. Analíticamente destaca GPT 51 U/I, amilasa 2019 U/I, PCR $8,96 \mathrm{mg} / \mathrm{l}, 11400$ leucocitos/ $\mu \mathrm{l}$ y tiempo de protrombina $58,2 \%$. La radiografía de tórax mostró derrame pleural derecho. Se realiza tomografía computarizada abdominal con hallazgo de colección líquida de $9 \times 8 \times 36 \mathrm{~mm}$ en la cabeza pancreática que se continúa con la crura diafragmática derecha y produce derrame pleural y atelectasia pulmonar adyacente (Figuras 1 y 2). El análisis del exudado pleural muestra amilasa aumentada (1200 U/I, normal hasta $120 \mathrm{U} / \mathrm{I})$. El paciente es ingresado y se inicia fluidoterapia, analgesia intravenosa y reposo intestinal con nutrición parenteral total. Se realiza colangiopancreatografía retrógrada endoscópica (CPRE) con colocación de prótesis pancreática plástica, con buena evolución clínica posterior. En pruebas de imagen de control se objetiva progresiva desaparición del derrame pleural.

La fístula pancreático-pleural es una complicación rara de la pancreatitis ${ }^{1,2}$. La fístula pancreática consiste en la disrupción inflamatoria del conducto pancreático, liberándose secreciones pancreáticas ${ }^{2,4}$. La disrupción anterior del ducto produce ascitis, mientras que la fuga posterior produce una fístula pancreático-

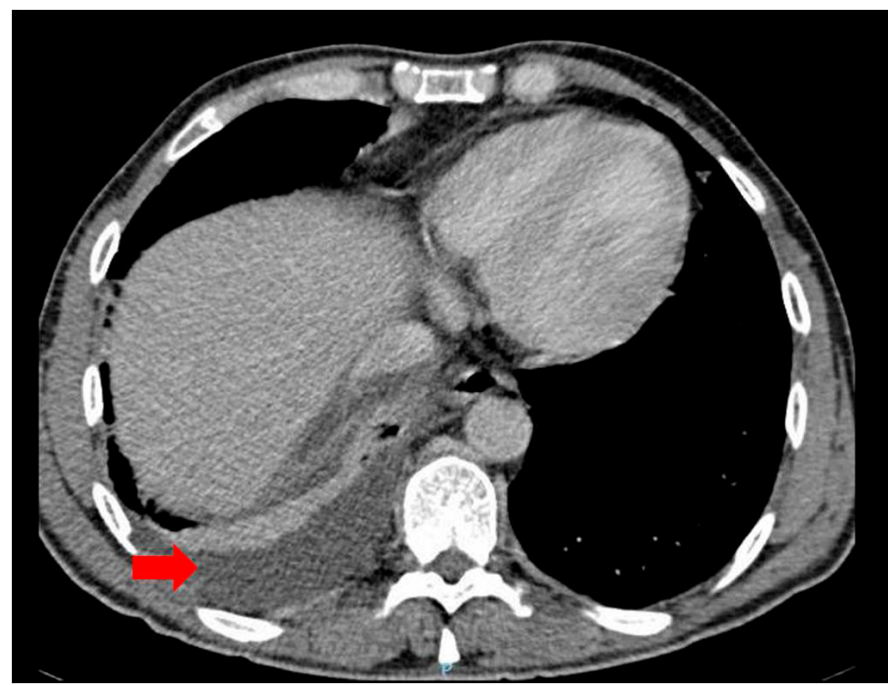

Figura 1

Corte transversal de tomografía computarizada abdominal en que se observa derrame pleural derecho.

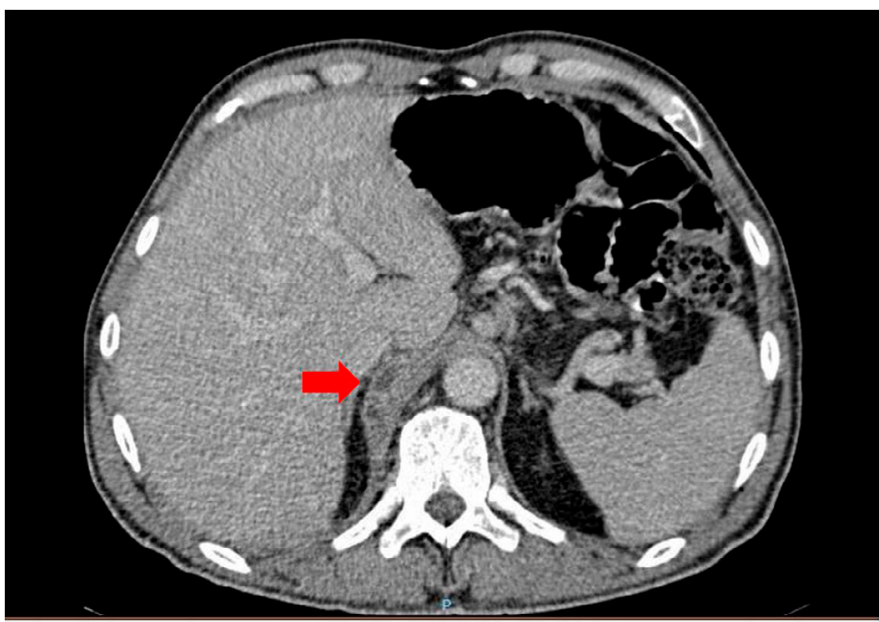

Figura 2

Corte transversal de tomografía computarizada abdominal que muestra crura diafragmática engrosada con zona de densidad líquida sugerente de fístula pancreático-pleural.

pleural ${ }^{3,4}$. El líquido pancreático asciende a través de aperturas anatómicas del diafragma, habitualmente el hiato esofágico y el aórtico ${ }^{3}$. El acúmulo torácico de líquido pancreático puede producir derrame pleural o un pseudoquiste pleural o mediastínico.

La incidencia de la fístula pancreático-pleural se estima en el $0,4 \%$ de los pacientes con pancreatitis ${ }^{2,4}$. Habitualmente afecta a hombres de edad media (40-50 años) con pancreatitis crónica alcohólica ${ }^{2,4}$. La clínica depende de la cantidad de líquido acumulada, e incluye dolor torácico, disfagia y disnea ${ }^{2,3}$. El diagnóstico se basa en pruebas de imagen, aunque a veces la fístula es difícil de visualizar ${ }^{2,3}$. El análisis bioquímico del líquido pleural con aumento de amilasa confirma el diagnóstico².

Las opciones terapéuticas incluyen manejo conservador y cirugía ${ }^{2,5}$. El manejo conservador tiene una tasa de éxito del 30-60\%1,2, y se puede valorar el drenaje de fluido pancreático y la colocación endoscópica de una prótesis pancreática ${ }^{2,3}$. Se recurre a la cirugía en caso de fallo del tratamiento médico o en presentaciones muy graves como sangrado, infección o rotura de un pseudoquiste ${ }^{2,3}$.

\section{Bibliografía}

1. Choe IS, Kim YS, Lee TH, Kim SM, Song KH, Koo HS, et al. Acute mediastinitis arising from pancreatic mediastinal fistula in recurrent pancreatitis. World Gastroenterol 2014;20(40):14997-15000.

2. Wypych K, Serafin Z, Gałązka P, Strześniewski P, Matuszczak W, Nierzwicka K, et al. Pancreaticopleural fistulas of different origin: Report of two cases and a review of literature. Pol J Radiol 2011;76(2):56-60.

3. Matsusue E, Fujihara Y, Maeda K, Okamoto M, Yanagitani A, Tanaka K, et al. Three cases of mediastinal pancreatic pseudocysts. Acta Radiol Open 2016;5(6):2058460116647213. 
4. Wronski M, Slodkowski M, Cebulski W, Moronczyk D, Krasnodebski IW. Optimizing management of pancreaticopleural fistulas. World J Gastroenterol 2011;17(42):4696-4703.
5. Iribarren Díaz M, de Castro Parga G, Díaz Cardamas P, Freiría Barreiro G, Pérez Domínguez L, Rivo Vázquez A, et al. Comunicación pancreático-pleural secundaria a pseudoquiste pancreático. Una complicación de evolución variable. Rev Esp Enferm Dig 2008;100(11):730-738. 